\title{
Mock juror age influences judgment of guilt and harshness of sentence on defendants with a record of 'borderline personality disorder'
}

\begin{abstract}
"Normal" legal proceedings do not take into consideration the unique needs of the accused who suffer from mental disorders. Individuals with a personality disorder, such as Borderline Personality Disorder (BPD), often exhibit antisocial behaviours which can lead to acts that contravene the law. When this occurs they can face court proceedings and may be found guilty of a criminal event. 160 male and female mock jurors (18-30 and 50+ years) were presented with a video depicting a court scene. There were four conditions: a control; no BPD record but symptoms; BPD record but no symptoms and BPD record with symptoms. Mock jurors rated the defendant for 'extent of guilt', 'criminal intent' and 'sentence'. Using MANOVA the main findings were that the $50+$ group rated defendants more punitively than the 18-30 year olds; male and females rated the defendant similarly and the 18-30 year olds rated defendants with BPD who exhibited symptoms the most leniently. The older generation appears to be harsher and tend to misattribute defendant BPD behaviours as bad and rude and should consequently be punished. This study provides support for how social behaviour, especially the behaviours of those with BPD, can influence juror deliberation.
\end{abstract}

Volume 5 Issue 4 - 2017

\author{
Sandie Taylor,Emily Alner, Lance Workman \\ School of Psychology and Therapeutic Studies, University of \\ South Wales, UK
}

Correspondence: Sandie Taylor, School of Psychology and Therapeutic Studies, University of South Wales, Pontypridd, Wales, CF37 IDL, UK, Email sandra.taylor@southwales.ac.uk

Received: October 02, 2017| Published: November 01, 2017

Keywords: mock jurors, verdict, justice, evidence, misattribute defendant

\section{Introduction}

The process of interpreting evidence in a court of law is pertinent for verdict deliberation. Evidence, however, is often open to a variety of interpretations. Studies have shown that factors other than evidential information presented in court can influence whether the verdict is 'guilty' or 'not guilty' and, in cases of 'mock jurors', can influence how punitive or lenient a sentence should be. Non-evidential information such as social and physical attributes pertaining to the defendant can influence juror decision-making. Non-evidential information is often used to refer to extra-legal defendant characteristics and has nothing to do with the criminal case being considered. Jurors in the courtroom are expected to evaluate the evidential information (the facts of the case) and base their verdict on these facts only. It is important for jurors to refrain from using non-evidential information during the deliberation process as it can be biased, subjective and often bound to Implicit Personality Theory (IPT) that encapsulates stereotypes and schemata about people. " $C$ ritics have claimed that the jury is swayed by subjective emotions, that its verdicts are often based upon unwarranted and irrational sympathies and prejudice". ${ }^{2}$ One reason why extra-legal defendant characteristics can have a detrimental effect on verdict determination relates to the objective of restoring equity to the criminal event. According to Lerner ${ }^{3,4}$ people have a belief in a 'just world'. This suggests that "we all have an understanding of our deservingness and a belief in the idea that others get what they deserve pending on what they have done". ${ }^{1}$ In relation to committing a crime, we want to restore equity to the situation such that the victim receives the justice deserved and the perpetrator is punished. This way of thinking ensures that the perpetrator gets his or her 'just deserts'. Therefore, if the evidential information is reliable and suggests culpability, then jurors are justified in finding the defendant guilty. If, however, they are basing their verdict on non-evidential information such as the way the defendant appears or behaves in the courtroom, and the evidential information is unreliable, then finding the defendant guilty is not meting out justice.

There is an expected decorum in the courtroom, not just for the players in court, such as the judge and lawyers for the prosecution and defense, but also for the defendant. A defendant who behaves in an argumentative, unpredictable, impulsive and emotionally erratic manner can be perceived by the jury as antisocial. This perception of the defendant is compared with IPT stipulating that certain traits are likely to co-occur. A person behaving in an antisocial manner is likely to be attributed with other negative traits which do not bode well with a criminal arrest and court hearing. Even if the defendant who behaves this way is innocent, jurors are likely to take this into account - hence, an extra-legal defendant characteristic. Jurors represent the rest of the population and are therefore likely to resort to using IPT when making judgements about defendants. They, like everyone else, use stereotypes and have preconceptions which influence their decision-making. ${ }^{5}$ In addition to the 'normal range' of personality characteristics considered as non-evidential information, an accused might also have a personality disorder which influences the way they behave. One such condition is called Borderline Personality Disorder (BPD). According to Reid et al., ${ }^{6}$ individuals with BPD appear in many different forensic/psychiatry contexts. Typical clinical symptoms include deficits in cognitive ability such as judgement making, perception, rationalisation and insight. Other problems pertain to the control and regulation of emotions and motivations and behaviour (in the form of impulsivity). 
Reid., ${ }^{6}$ further points out that these symptoms are often misunderstood by people and, importantly, by judges and jurors. The situation for jurors becomes even more difficult if there is a failure to properly diagnose a personality disorder. ${ }^{7}$ Despite the Minnesota Multiphasic Personality Inventory (MMPI) and the Personality Assessment Inventory (PAI) being commonly used to assess for BPD traits, they fail to provide for a clear diagnosis of the disorder. ${ }^{89} \mathrm{BPD}$ and Antisocial Personality Disorder (APD), according to Howard et al., ${ }^{10}$ comprise of a cluster of criminogenic traits which can lead to a criminal lifestyle and are therefore overrepresented in prison. The New Jersey Supreme Court ruled in, ${ }^{11}$ that a defendant with BPD had cognitive deficits which interfered with their ability to elicit purposeful action. This thereby increases the chances of committing serious criminal acts such as homicide. According to Gilbert et al., ${ }^{12}$ individuals with a personality disorder are far more likely to be reconvicted for murder, rape, assault and manslaughter than those who have not been diagnosed with a personality disorder. Ross et al., ${ }^{13} \mathrm{claim}$ that both APD and BPD individuals are more likely to show violence towards an intimate partner. In a study examining staff perceptions of their patients with various personality disorders and the attribution of cause for their condition, Fraser et al., ${ }^{14}$ found that patients with BPD were rated more negatively by staff members than an unimpaired comparison group. Patients' negative behaviours were considered to be a feature of BPD and furthermore to be in their control. These findings lend support to the view that BPD is perceived negatively and corresponds to negative stereotyping by others. ${ }^{15}$ Moreover, Wallace claims that such negative perceptions and stereotypes can lead to "unfavourable judgements and verdict choices." 18

Wallace ${ }^{15}$ found that mock jurors rated sympathy for an offender with a mental illness (schizophrenia and BPD) similarly to the control group. Mock jurors were more likely to sentence defendants with schizophrenia or BPD to a psychiatric institution than those in the control group. Interestingly, however, just below 50 percent of mock jurors sentenced schizophrenic and BPD defendants to a term in prison for their crimes. This meant just over 50 percent of mock jurors recommended defendants be incarcerated in a psychiatric institution despite finding them guilty. It appears, therefore, that a defendant's mental state influences a host of decisions regarding criminal proceedings: detention, interrogation, diversion, prosecution, conviction, disposal, treatment and release ${ }^{16}$ Hogget $^{17}$ notes, "the fact that a person who is alleged to have committed a criminal offence may be mentally disordered can affect the normal process of the law" (p. 97). Additionally, this has implications for labelling and stigmatisation and might affect jurors' opinions and subsequent judgement of the defendant.

Interestingly, defendants with a mental disorder are not the only ones to be treated differently. The Criminal Statistics for England and Wales in 1995 indicated that twice as many males as females received a custodial sentence. ${ }^{18}$ Spohn et al., ${ }^{19}$ found that female defendants were more likely to have charges against them dropped and, when they were sentenced, they received lighter sentences than their male counterparts. A Home Office study conducted by Hedderman et al., ${ }^{20}$ showed that females were treated more leniently by the criminal justice system than were males. Results from Hedderman et al., ${ }^{20}$ study surveying attitudes held by 200 magistrates, supported the view that women are often treated differently from men due to the fact that they were rarely seen in court and that they were considered as 'troubled' rather than 'troublesome.' Allen ${ }^{21}$ found that violent women offenders received more sympathetic justice than men and were often treated through psychiatric means. Studies have shown that the majority of women in prison have some kind of mental disorder. Tye et al., ${ }^{22}$ for instance, researched the rates of mental disorders amongst female inmates in the Australian state of Victoria and compared this with community rates. They found that 43 percent of these women met the criteria for a personality disorder. Fazel et al., ${ }^{23}$ uncovered a similar percentage (42 percent) from 62 surveys conducted in 12 different countries.

Beckham et al., ${ }^{24}$ claim that verdict outcomes can be influenced by the gender and age of the mock juror. Studies have also shown that gender is a reliable predictor of verdicts rendered. For instance, female jurors are more likely to convict defendants for child molestation; ${ }^{25}$ for rape, ${ }^{26-28}$ and for sexual harassment, ${ }^{29}$ than are men. Schutte etal., ${ }^{30}$ performed a meta-analysis on gender differences in sexual assault verdicts. They found that women are more likely to convict in these cases than men. Moreover, females tend to identify with the victim, ${ }^{31,32}$ blame the defendant and judge more punitively, ${ }^{33}$ and provide stiffer sentences, ${ }^{34}$ in sexually-related cases than males. Research in the field of sex differences in mock juror decision making, however, appears to be influenced by other factors. In other words, differences in strictness of sentencing by the sexes may be a function of the types of crime committed by the defendant and/ or the defendant's justification for the act. The latter has proven to be the case. ${ }^{35}$ The age of the juror has also been considered in mock jury research. Mossière et al. ${ }^{36}$ found differences of verdicts and sentences across gender and age for a defendant labelled a 'psychopath' (i.e. a personality disorder). They failed to find any gender bias but obtained a significant interaction between the age of the juror and measures of verdict and type of sentence. The younger mock jurors tended to opt for a guilty verdict but recommended probation whereas the older age groups provided a not guilty verdict and imprisonment for those they did find guilty. These differences demonstrate a wide margin in decision making across the younger and older mock jurors. Higgins etal., ${ }^{37}$ investigated the effects of mock juror age on variables of defendant age and crime justification, such as having a cocaine dependency disorder or posttraumatic stress disorder. The older mock jurors judged the defendant as more responsible for his criminal actions in the high self-inflicted condition (i.e. cocaine dependency disorder) than the younger group of jurors. Moreover, the cocaine dependency defendants were more likely to receive a guilty verdict and longer sentence than the less self-inflicted defendants (i.e. those with posttraumatic stress disorder). Posttraumatic stress disorder is classified as a mental condition resulting from a highly stressful experience unlike cocaine dependency disorder which is based on a decision to use drugs. Mock jurors were more sympathetic to the former mental condition. ${ }^{38}$

\section{The present study}

In this study we aim to combine some of the previously discussed extra-legal defendant and mock juror characteristics together in order to investigate the perceptions and judgements held by male and female mock jurors varying in age for defendants exhibiting the behavioural symptoms of borderline personality disorder (BPD).

i. Hypothesis $1\left(\mathrm{H}^{1}\right)$ states that the $50+$ age group will rate defendants who have a record of BPD and exhibit symptoms more harshly on 'extent of guilt', 'criminal intent' and 'sentencing' than the 18-30 age group. 
ii. Hypothesis $2\left(\mathrm{H}^{2}\right)$ states that defendants with a record of BPD without symptoms of BPD will have a higher extent of guilt rating; attributed as having higher criminal intent and sentenced more harshly than the control condition.

iii. Hypothesis $3\left(\mathrm{H}^{3}\right)$ states that the sex of the mock juror will have an effect on all ratings of the defendant.

\section{Method}

\section{Participants}

160 male and female mock jurors were divided according to age such that 80 comprised the $18-30$ year olds and 80 the 50+ group. Each mock juror was randomly assigned to one of four conditions. This meant that each condition had 20 mock jurors from the 18-30 year olds (10 males and 10 females) and 20 from the older group (10 males and 10 females). Hence, there were 40 mock jurors in total per condition.

\section{Design}

A $4 \times 2$ independent design was adopted whereby there were four conditions - one of which was the control group.

a) Condition 1 (control group): the defendant has no record of BPD and shows no symptoms,

b) Condition 2: the defendant has no record of BPD but shows symptoms,

c) Condition 3: the defendant has a record of BPD but shows no symptoms,

d) Condition 4: the defendant has a record of BPD and shows symptoms.

\section{Materials and procedure}

A fictitious court scene was presented in the format of video. There were four videos featuring voluntary actors acting from a written transcript. The transcript for each condition was held constant, apart from conditions where there was mention of the defendant having a record of BPD. For these conditions an expert psychologist provided evidence of a history of BPD. In conditions where the symptoms of BPD were overt, this was portrayed by the defendant actor in the video footage. After viewing the footage, mock jurors were provided with scoring sheets to rate 'extent of guilt', 'criminal intent' and 'sentencing' independently. Each scoring sheet was based on an interval scale where ' 0 ' represented 'no guilt', 'no criminal intent' and 'no sentence'. This scale incremented by ' 1 ' representing in the case of 'extent of guilt' and 'criminal intent', 10 percent and ' 10 ' equalling 100 percent. In the case of sentence, a monetary sum incremented accordingly.

\section{Results}

All variables were inputted into a MANOVA analysis. This uncovered the following findings (please note that (Figures 1-3) illustrate findings for point four):

i. Age group and extent of guilt $(\mathrm{F}(1,144)=11.483, \mathrm{p}<0.001)$; age group and criminal intent $(\mathrm{F}(1,144)=90.907, \mathrm{p}<0.001)$; and age group and sentence $(F(1,144)=73.699, \mathrm{p}<0.001)$ were all statistically significant. Age group is influencing the scores, with the older group scoring more harshly on all three measures. Hence, data analyses supported $\mathrm{H}_{1}$.

ii. Condition and extent of guilt $(\mathrm{F}(1,144)=7.263, \mathrm{p}<0.001)$; condition and criminal intent $(\mathrm{F}(1,144)=50.902, \mathrm{p}<0.001)$; and condition and sentence $(\mathrm{F}(1,144)=17.755, \mathrm{p}<0.001)$ revealed that differences go in the direction predicted in $\mathrm{H}_{2}$.

iii. Gender and extent of guilt $(\mathrm{F}(1,144)=0.990, \mathrm{p}>0.05)$; gender and criminal intent $(\mathrm{F}(1,144)=4.435, \mathrm{p}<0.05)$; and gender and sentence $(F(1,144)=2.749, p>0.05)$ revealed that there was a difference in scoring between males and females for criminal intent only, with males scoring higher. The analyses failed to support $\mathrm{H}_{3}$

iv. Age group, condition and extent of guilt, criminal intent and sentence were all significant $(\mathrm{F}(3,144)=8.354, \mathrm{p}<0.001)$; $(\mathrm{F}(3,144)=16.196, \quad \mathrm{p}<0.001) ; \quad(\mathrm{F}(3,144)=15.217, \quad \mathrm{p}<0.001)$ respectively (Figures 1-3).

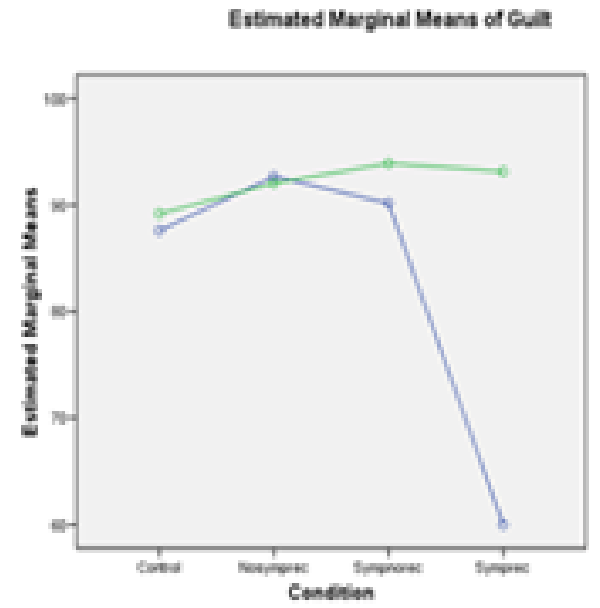

Figure I Age group and condition on extent of guilt scores.

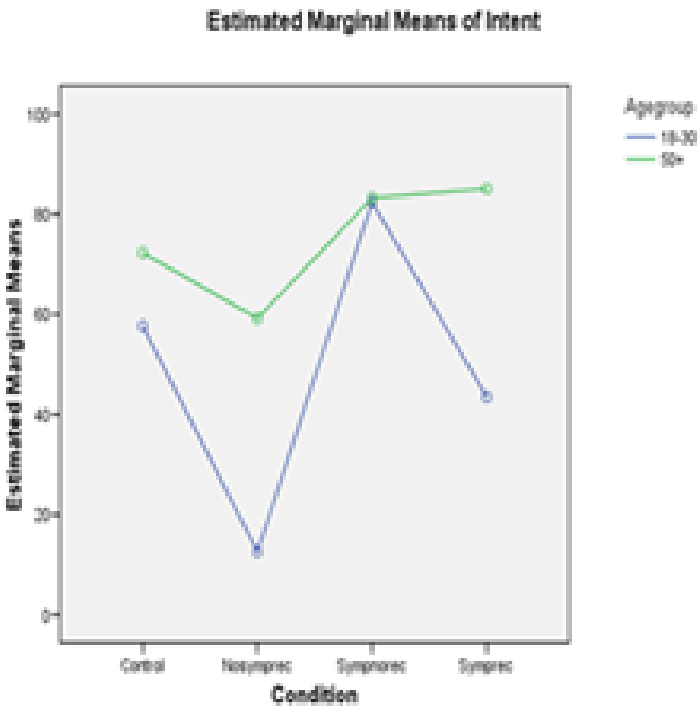

Figure 2 Age group and condition on criminal intent scores. 


\section{Estimated Marginal Means of Sentence}

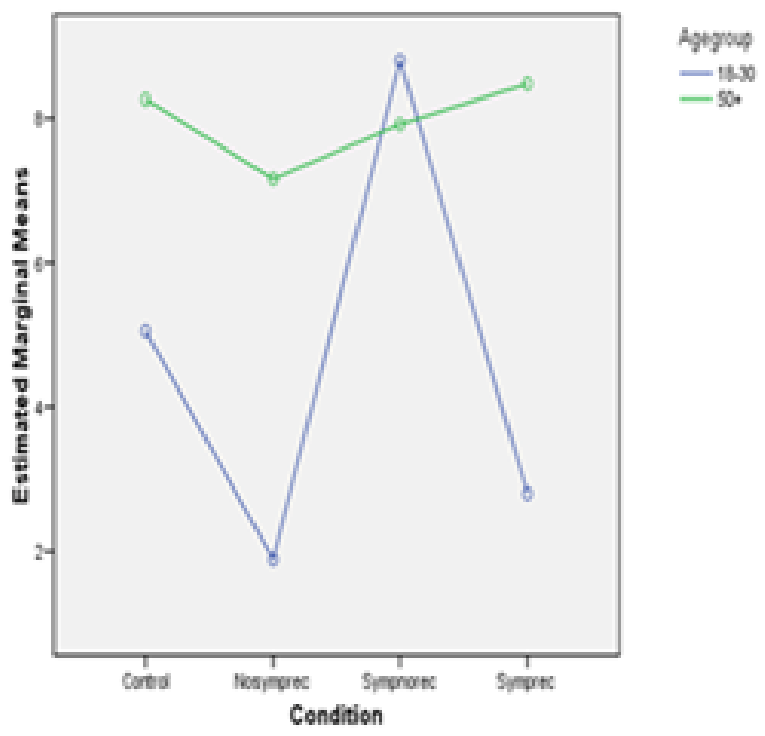

Figure 3 Age group and condition on sentence scores.

\section{Discussion}

While gender was not a significant factor (providing little support for $\mathrm{H}_{3}$ ) in the scoring of extent of guilt, criminal intent (with the exception of males who scored higher on this measure) and sentencing, age group was statistically significant. Across all four conditions, the age group 50+ consistently scored extent of guilt and criminal intent higher and also gave longer sentences than the 1830 age group. Hence, the analyses provided support for $\mathrm{H}_{1}$. The aim of this study was to examine the effects of having a mental record (or not) along with (or without) overt symptoms on mock jurors' verdicts. It might be argued that, due to increasing information and understanding of mental illness (i.e. BPD) over the last 25years, the younger age group 18-30 are more likely to judge and sentence the defendant less harshly than the older group. The study showed this to be the case. It is assumed that the older groups $50+$ are likely to be less informed about mental illness, have less understanding and are also from a stricter, more disciplined, era. It could be that the older group were scoring more harshly because they were brought up at a time when rules and discipline were more strictly applied than today. Additionally, the older group scored higher than the younger group across all conditions, indicating that whether the defendant had a mental disorder or not, showed overt symptoms or not, what mattered was that a crime had been committed and was punishable.

This conforms to the research findings of Izzett and Fishman who found that the justification of the criminal act outweighed any other extra-legal defendant characteristics. Older mock jurors appear to be using concepts of justifiability and accountability for a criminal act in deciding a guilty verdict and length of sentence. ${ }^{37}$ These concepts were controlled for by using depictions of high or low self-infliction (cocaine dependency disorder versus posttraumatic stress disorder respectively). This suggests that decisions made by the older mock jurors may be based on justification for the action. This fits in with
Lerner's concept of a belief in a just world and that people persevere in restoring a sense of justice to an inequitable situation, such as that between victim and defendant. While in Higgins et al. study, the older mock jurors considered the mental health of the defendant (albeit with low self-infliction), this was not the case here. There is an important difference, however. In this study, BPD may well have been perceived by the older mock jurors as an excuse for bad behaviour. Relating back to the point discussed earlier that older mock jurors are less likely to be informed about BPD than younger groups, it is likely that the symptoms of BPD are considered to be antisocial. Moreover, the older group may well have held the view that antisocial behaviour should be punished and, for this reason, all conditions were rated similarly.

Results across the conditions for 'extent of guilt' indicate that for the 18-30 age group, the most harshly scored condition was the BPD record without symptoms, followed closely by the no BPD record with symptoms and the control condition. The leniently scored condition was the BPD record with symptoms. The condition describing the defendant as having a record of BPD without exhibiting symptoms was scored as high as the control and the no BPD but symptoms condition. It is speculated that this might be due, in part, to the perceptions of the defendant in these three groups being similar. A defendant with a record of BPD, but showing little evidence of it, might be perceived as an individual trying to receive leniency and a reduced sentence. A defendant showing bad behaviour in court but with no record of BPD can be perceived as an ill-behaved individual and, if anything, could potentially be judged more punitively than both the control group and the defendant who has a BPD record. Results between these three conditions were undifferentiated enough to be significant, but lend support to $\mathrm{H}_{2}$ in that defendants with a record of BPD without symptoms were rated harshly. Their ratings, however, were not that dissimilar from the defendant without a record of BPD but showing symptoms and the control.

In the case of criminal intent, the most harshly scored condition was 'no BPD record but demonstrating symptoms of it.' This finding supports the above point made about potentially being perceived more negatively than the control. The most leniently scored condition was for the 'BPD record but without overt symptoms', followed by 'BPD record with symptoms.' This did not support the predicted direction of $\mathrm{H}_{2}$. In the case of sentence, the most punitive scores were reserved for the 'no BPD record but showing overt symptoms.' The least punitive was for the 'BPD record with no symptoms' followed closely by the 'BPD record with symptoms.' This did not support the predicted direction of $\mathrm{H}_{2}$.

\section{Conclusion}

These findings offer evidence in support of extra-legal defendant characteristics (social behaviour as a consequence of a personality disorder) affecting deliberation decisions. The younger mock jurors tended to rate defendants who have a record of BPD either with or without symptoms more leniently for criminal intent and sentence. In the case of 'extent of guilt' only the condition where the defendant had BPD and showed symptoms was rated leniently. The defendant with a record of BPD but without symptoms was rated harshly on a par with the control and the defendant who exhibited symptoms of BPD. Findings suggest that older mock jurors were far harsher in their ratings and, arguably misattribute the behaviours shown by those with BPD for 'bad', 'rude' and 'punishable' behaviour. 


\section{Acknowledgments}

None.

\section{Conflicts of interest}

The author declares that there are no conflicts of interest.

\section{Funding}

None.

\section{References}

1. Taylor S. Crime and criminality: A multidisciplinary approach. USA: Taylor and Francis. 2016:1-800.

2. Hans VP, Vidmar N. Judging the Jury. Michigan Law Review. 1987;85(56):1240-1245.

3. Lerner M. The unjust consequences of the need to believe in a just world In: Sales BD, editors. Perspectives in law and psychology: Volume 2: The jury, judicial and trial processes. USA: Plenum. 1966.

4. Lerner M. The belief in a just world: A fundamental delusion. USA: Plenum. 1980;1-210.

5. Skeem J, Golding S. Describing jurors' personal conceptions of insanity and their relationship to case judgments. Psychology, Public Policy, and Law. 2001;7(3):561-621.

6. Reid WH. Borderline personality disorder and related traits in forensic psychiatry. J Psychiatr Pract. 2009;15(3):216-220.

7. Johnson SC, Elbogen EB. Personality disorders at the interface of psychiatry and the law: Legal use and clinical classification. Dialogues Clin Neurosci. 2013;15(2):203-211

8. Borum R, Grisso T. Psychological test use in criminal forensic evaluations Professional Psychology. 1995;26:465-473.

9. Bow JN, Flens JR, Gould JW. MMPI-2 and MCMI-1ll in forensic evaluations: A survey of psychologists. Journal of Forensic Psychological Practice. 2010;10(1):37-52

10. Howard RC, Huband N, Duggan C, et al. Exploring the link between personality disorder and criminality in a community sample. J Pers Disord. 2008;22(6):589-603.

11. State v. Gallaway.133 NJ. 1993;631: 628A-735

12. Gilbert F, Daffern M. Illuminating the relationship between personality disorder and violence: Contributions of the general aggression model. Psychology of Violence. 2011;1(3):230-244.

13. Ross J, Babcock JC. Proactive and reactive violence among intimate partner violent men diagnosed with antisocial and borderline personality disorder. Journal of Family Violence. 2009;24(8):607-617.

14. Fraser K, Gallop R. Nurses' confirming/disconfirming responses to patients diagnosed with borderline personality disorder. Arch Psychiatr Nurs. 1993;7(6):336-341.

15. Wallace K. Perceptions of mental illness in the legal system. (Unpublished dissertation) Georgia State University, USA. 2012.

16. Bartlett P, Sandland R. Mental Health Law: Policy and Practice. UK: Blackstone Press. 2000;1-669.

17. Hogget B. Mental health law. UK: Sweet and Maxwell. 1996.

18. Flood-Page C, Mackie A. Sentencing Practice: An examination of decisions in magistrates' courts and the Crown Court in the mid-1990's. UK: Home Office Research Study. 1998.
19. Spohn CC, Spears JW. Gender and case processing decisions: A comparison of case outcomes for male and female defendants charged with violent felonies. Journal of Women and Criminal Justice. 2008;8(3):29-59.

20. Hedderman C, Gelsthorpe L. Understanding the sentencing of women USA: Home Office Research Studies. 1997;1-98.

21. Allen H. Justice unbalanced: Gender, psychiatry and judicial decisions UK: Open University Press. 1987.

22. Tye CS, Mullen PE. Mental disorders in female prisoners. Aust NZJ Psychiatry. 2006;40(3):266-271.

23. Fazel S, Danesh P. Serious mental disorder in 23,000 prisoners: A systematic review of 62 surveys. The Lancet. 2002;359(9306):545-550.

24. Beckham CM, Spray BJ, Pietz CA. Jurors' locus of control and defendants' attractiveness in death penalty sentencing. J Soc Psychol. 2007;147(3):285-298

25. Kovera MB, Gresham AW, Borgida E, et al. Does expert psychological testimony inform or influence juror decision making? A social cognitive analysis. J Appl Psychol. 1997;82(1):178-191.

26. Brekke N, Borgida E. Expert psychological testimony in rape trials: A social-cognitive analysis. Journal of Personality and Social Psychology. 1988;55(3):372-386.

27. Freetly AJ, Kane EW. Men's and women's perceptions of non-consensua sexual intercourse. Sex Roles. 1995;33(11-12):785-802.

28. Hyme HS, Foley LA, Pigott MA. A comparison of male and female dominated juries in a case of coerced sex with a male plaintiff. American Journal of Forensic Psychology. 1999;17(3):67-80.

29. Kovera MB, McAuliff BD, Hebert KS. Reasoning about scientific evidence: Effects of juror gender and evidence quality on juror decisions in a hostile work environment case. J Appl Psychol. 1999;84(3):362-375.

30. Schutte JW, Hosch HM. Gender differences in sexual assault verdicts: A metaanalysis. Journal of Social Behavior and Personality. 1997;12(3):759-772.

31. Gerdes EP, Dammann EJ, Heilig KE. Perceptions of rape victims and assailants: Effects of physical attractiveness, acquaintance, and subject gender. Sex Roles. 1988;19(3-4):141-153.

32. Smith RE, Keating P, Hester RK, et al. Role and justice considerations in the attribution of responsibility to a rape victim. Journal of Research in Personality. 1976;10(3):346-357.

33. Macrae CN, Shepherd JW. Sex differences in the perception of rape victims. Journal of Interpersonal Violence. 1989;4(3):278-288.

34. Scroggs JR. Penalties for rape as a function of victim provocativeness, damage, and resistance. Journal of Applied Social Psychology. 1976;6(4):360-368

35. Izzett RR, Fishman L. Defendant sentences as a function of attractiveness and justification for actions. The Journal of Social Psychology. $1976 ; 100(2): 271-279$

36. Mossière A, Dalby JT. The influence of gender and age in mock juror decision-making. Europe's Journal of Psychology. 2008;4(4).

37. Higgins PL, Heath WP, Grannemann BD. How type of excuse defense, mock juror age, and defendant age affect mock jurors' decisions. $J$ Soc Psychol. 2007;147(4):371-392.

38. Gelsthorpe L, Loucks N. Magistrates' explanations of sentencing decisions. In: Hedderman C, Gelsthorpe L, editors. Understanding the Sentencing of Women. UK: 1997. 